Article

\title{
Plasma Aromatase Activity Index, Gonadotropins and Estrone Are Associated with Frailty Syndrome in Post-Menopausal Women with Breast Cancer
}

\author{
Javier García-Sánchez ${ }^{1,2}$, Mayra Alejandra Mafla-España ${ }^{3,4}$, Carlos Tejedor-Cabrera ${ }^{4}$, Olga Avellán-Castillo ${ }^{4}$, \\ María Dolores Torregrosa ${ }^{1}$ and Omar Cauli ${ }^{3,4, * \mathbb{D}}$
}

1 Medical Oncology Department, Doctor Peset University Hospital, 46017 Valencia, Spain; javier.garciasanchez@chwapi.be (J.G.-S.); torregrosa_dol@gva.es (M.D.T.)

2 Medical Oncology Department, Hospital Center of Wallonie Picardy, 7500 Tournai, Belgium

3 Frailty Research Organized Group, University of Valencia, 46010 Valencia, Spain; maymaes@alumni.uv.es

4 Department of Nursing, University of Valencia, 46010 Valencia, Spain; carteca@alumni.uv.es (C.T.-C.); olacas@alumni.uv.es (O.A.-C.)

* Correspondence: omar.cauli@uv.es

check for updates

Citation: García-Sánchez, J.;

Mafla-España, M.A.; Tejedor-Cabrera, C.; Avellán-Castillo, O.; Torregrosa, M.D.; Cauli, O. Plasma Aromatase Activity Index, Gonadotropins and Estrone Are Associated with Frailty Syndrome in Post-Menopausal Women with Breast Cancer. Curr. Oncol. 2022, 29, 1744-1760. https:// doi.org/10.3390/curroncol29030144

Received: 10 December 2021

Accepted: 4 March 2022

Published: 7 March 2022

Publisher's Note: MDPI stays neutral with regard to jurisdictional claims in published maps and institutional affiliations.

Copyright: (C) 2022 by the authors. Licensee MDPI, Basel, Switzerland. This article is an open access article distributed under the terms and conditions of the Creative Commons Attribution (CC BY) license (https:// creativecommons.org/licenses/by/ $4.0 /)$.

\begin{abstract}
Frailty syndrome is associated with poor outcomes, morbidity and premature mortality. We performed a cross-sectional study to evaluate the presence of frailty syndrome based on Fried's frailty phenotype in post-menopausal women with breast cancer. We further analyzed the association between frailty syndrome with geriatric assessments and the association with the concentration of gonadotropins LH and FSH, estrogens, androgens and the aromatase activity index in the blood. We enrolled 47 post-menopausal women with localized breast cancer (mean age $66.8 \pm 1.3$ years (range 52-83)) prior to the starting of adjuvant endocrine therapy. Patients were identified as "nonfrail" (robust) or "prefrail/frail" if they fulfilled at least one frailty criteria. In order to determine associations among variables and to control for other variables potentially affecting frailty syndrome (age, comorbidity index and previous chemotherapy treatment), we performed a logistic regression analysis. The receiver operating characteristic curve was performed to assess the sensitivity and specificity of the hormonal concentration to discriminate prefrail/frail versus non-frail individuals. Significant positive associations were observed between the severity of frailty syndrome and estrone, FSH and LH concentrations and the aromatase activity index in the blood $(p<0.05)$. Further research into the role of hormonal biomarkers should be evaluated in follow-up studies in order to recommend their use as suitable biomarkers of frailty syndrome in breast cancer patients.
\end{abstract}

Keywords: ageing; breast cancer; biomarker; geriatric evaluation; oncogeriatrics; side effect; androgen; estrogens

\section{Introduction}

The increased incidence and improved diagnostic and therapeutic interventions over the past decades have led to a rise in the prevalence of oncological diseases among the older patients [1]. According to the World Cancer Observatory (2019) [2], breast cancer mortality has fallen by $30 \%$ in the last 20 years, although it continues to rank among the five leading causes of oncological mortality in Spain and worldwide [3]. The physiological changes occurring during aging processes increase the risk of malignancies, as well frailty syndrome, which represents a state of increased vulnerability resulting from aging-associated decline in reserve and function across multiple physiologic systems, such that the ability to cope with acute stressors is compromised [4]. This syndrome involves physical deterioration and the loss of functions due to the loss of physiological reserves in the process of aging [5] or as a consequence of some chronic diseases [6]. The onset of frailty syndrome may limit therapeutic options and prognosis due to its numerous consequences, such as a lack of 
adherence to treatment and increased risk of disability, dependence, comorbidity and death [6]. The pathophysiological basis of frailty syndrome includes several systems such as the immune, muscular and endocrine systems, with the latter including estrogens and androgen hormones [7].

Geriatric assessment in oncology patients in clinical practice are useful and are able to detect frail patients. The International Society of Geriatric Oncology has established recommendations on the performance of geriatric assessments: they can lead to the detection of previously unidentified problems and risks for which specific interventions can be applied and to the prediction of adverse outcomes (e.g., toxicity of a therapy or functional or cognitive impairment) [8]. The primary goal of geriatric assessment is to provide a comprehensive health assessment to guide specific interventions and help select the appropriate cancer treatment. The geriatric assessment includes at least assessment of functional status, cognition and mood. Regarding evaluation of the functional assessment, measurements of a frailty phenotype based on physical criteria (low grip strength, low energy, slowed walking speed, low physical activity and/or unintentional weight loss) proposed by Fried and co-workers could be useful to identify frail individuals [9].

Menopause and menopause-related characteristics has been reported to be a predisposing factor for frailty syndrome [10]. The dramatic decline in hormone concentrations observed in menopause may account for the increased prevalence of both frailty and sarcopenia in women compared to men [11,12]. Many studies found that blood testosterone concentrations, and free testosterone concentrations in particular, are significantly lower in frail individuals of both genders [13-15], although mixed results were reported in women [16]. Different changes in dehydroepiandrosterone (DHEA) levels in the blood have been also associated with frailty, with higher levels in men [17], and lower DHEA levels have been reported in the serum of frail subjects [18,19]. The concentration of estrogens, estradiol and estrone has been also associated with frailty syndrome in older men, although with mixed results in different studies [16,20-22]. In contrast, higher estradiol levels in older women have been associated with frailty [16]. The decline in estrogen production that occurs during menopause is also recognized as being one of the causes of the deterioration of women's health, affecting the loss of muscle mass and strength, which represents the pillar of sarcopenia, a geriatric syndrome that partially overlaps with frailty syndrome [10]. A recent study performed in older women with early breast cancer identified a high prevalence of low muscle mass in the whole sample (almost $42.7 \%$ ), almost equally distributed in frail and non-frail patients. However, when more stringent criteria that incorporate muscle function (such as EWGSOP 2) were used, only a limited proportion of patients (26\%) could still be defined as "sarcopenic". Indeed, severely sarcopenic patients were almost always classified as frail on the results of comprehensive geriatric assessment [23]. Both sarcopenia and frailty are affected by hormonal changes and tumor and cancer treatment [23-25].

Estrogens such as estradiol (predominant estrogen in premenopausal women) and estrone (predominant estrogen after menopause) in particular, and to a lesser extent androgens, have a direct influence on the onset, progression and cure of most cases of breast cancer $[10,26]$. The development of specific biomarkers for the detection of frailty is one of the most current fields of research for diagnosis, prognosis and treatment [27]. The study of the hormonal alterations associated with frailty syndrome in breast cancer patients could help clinical practice to detect frailty syndrome in at-risk groups and design strategies to prevent or delay its onset. The main objectives of the study were:

- $\quad$ To describe the presence of frailty syndrome and its severity in postmenopausal women with hormone-dependent breast cancer before starting hormonal therapy.

- $\quad$ To determine whether frailty syndrome is associated with alterations in geriatric assessment.

- $\quad$ To ascertain whether frailty syndrome and geriatric assessment are associated with hormonal gonadal alterations in androgens and estrogens, gonadotropins levels, and the aromatase activity index in the blood. 


\section{Methods}

\subsection{Design and Study Population}

An analytical, cross-sectional study was performed. The study included postmenopausal women diagnosed with hormone-dependent early breast cancer who had undergone surgery to remove the tumor, radiotherapy and or chemotherapy and who were prior to receiving anti-estrogen treatment to prevent recurrence. The recruitment and evaluation were performed by the medical oncology service of the university hospital Doctor Peset in Valencia (Spain), during the last quarter of 2019 and first quarter of 2020. The exclusion criteria were refusal to participate by the women after being informed of the study objectives or failing to understand the Spanish language correctly. A total of 47 women agreed to participate and signed the informed consent. The study was approved by the clinical research ethics committee of the Hospital Doctor Peset university hospital (protocol code $57 / 18$, approved on 5 July 2018).

\subsection{Assessment of Frailty Syndrome}

The assessment of the frailty syndrome was performed according to Fried's five criteria, such that the presence of three of these criteria would indicate a frailty state [9]. The criteria were assessed as follows: (1) weight loss, defined as unintentional loss of $4.5 \mathrm{~kg}$ or more in the past year. (2) Self-reported exhaustion, assessed by the question "how often in the last week did you feel that everything you did involved fatigue?", included on the Center for Epidemiological Studies of Depression (CES-D) Scale [28]. It was considered positive when the answer was "often" or "most of the time". (3) Decreased physical activity, assessed with the International Physical Activity Questionnaire (IPAQ), validated in Spanish. The time spent during a week was divided into quintiles, and the lowest quintile (20\% less active) was given a positive score for this criterion [29]. (4) Motor slowness, calculated using the 4.6-m walking gait test and considered positive when the participant was in the lowest quintile, after adjustment for height according to the "Short Physical Performance Battery" [30]. The cutoff was set at $7 \mathrm{~s}$ for participants with a height $\geq 1.59 \mathrm{~m}$ and at $6 \mathrm{~s}$ for participants with a height $<1.59 \mathrm{~m}$. (5) Low muscle strength. Overall muscle condition was calculated based on handgrip strength measured with a digital hand-held dynamometer. The positive criterion was given to the last quintile recorded in the sample (20\% less strength) [31]. Frailty defined using the frailty phenotype based on Fried' criteria classified individuals as pre-frail if they fulfilled one or two criteria or frail if they fulfilled three or more. Participants that did not fulfill any criteria were classified as robust [9].

\subsection{Geriatric Assessment}

The cognitive status was assessed with the validated version of the Mini Cognitive Examination (MEC) [32]. Depressive symptoms were measured with the Geriatric Depression Scale (GDS-15) [33,34]. Functional status was assessed using the Barthel Index [35]. Nutritional status was assessed using the Spanish validated version of the Mini Nutritional Assessment (MNA) [36]. Body Mass Index (BMI) was adjusted for age according to the WHO recommendations. For participants under 65 years of age, BMI was calculated based on the following groups: $<18.5 \mathrm{~kg} / \mathrm{m}^{2}$ (underweight), $18.5-24.9 \mathrm{~kg} / \mathrm{m}^{2}$ (normoweight), $25-29.9 \mathrm{~kg} / \mathrm{m}^{2}$ (overweight) and $\geq 30$ (obese). For participants older than 64 years, BMI was calculated based on the following groups: $<16 \mathrm{~kg} / \mathrm{m}^{2}$ (severe malnutrition), $16.1-18.4 \mathrm{~kg} / \mathrm{m}^{2}$ (moderate malnutrition), $18.5-22 \mathrm{~kg} / \mathrm{m}^{2}$ (underweight), $22.1-24.9 \mathrm{~kg} / \mathrm{m}^{2}$ (normoweight), $25-29.9 \mathrm{~kg} / \mathrm{m}^{2}$ (overweight) and $\geq 30 \mathrm{~kg} / \mathrm{m}^{2}$ (obesity) [37]. Circumferences of the arm ( $<27 \mathrm{~cm}$ implies low muscle mass), calf $(<32.5 \mathrm{~cm}$ implies low muscle mass), hip ( $>99 \mathrm{~cm}$ implies high fat mass) and abdomen $(>85.9 \mathrm{~cm}$ implies high fat mass) were also measured [38,39]. The Athens Insomnia Scale was used to evaluate sleep quality $[40,41]$. The Charlson index was used to assess the comorbidity index [42]. 


\subsection{Measurement of Hormones in Plasma}

Blood samples were collected at between 9-10 a.m., under fasting conditions. After collection, blood samples were centrifuged at room temperature at $1500 \mathrm{rpm}$ for $5 \mathrm{~min}$. The supernatant was stored in $1 \mathrm{~mL}$ aliquots and frozen at $-20{ }^{\circ} \mathrm{C}$ until analytical analysis, which took place within 3 days of blood collection. The concentrations of FSH, LH, estradiol, progesterone, testosterone and dehydroepiandrosterone sulfate were measured by the chemiluminescent microparticle immunoassay (CMIA). The dihydrotestosterone, androstenedione and estrone concentrations were measured using the ELISA Kit (CloudClone Corp. Houston, TX, USA ref. CC-IEA443Ge, CC-IEA456Ge and Arbor assays ref. AA-K031-H5, respectively). Hormone levels were extrapolated from the standard solution curve.

\subsection{Aromatase Activity Index in Plasma}

The aromatase (the enzyme transforming androgens into estrogens) activity index in plasma was evaluated by calculating the ratio between the concentrations of estrone over androstendione in the blood, as a suitable index of aromatase activity in post-menopausal women $[43,44]$. The concentrations of aromatase in plasma was measured by the ELISA Kit (Cloud-Clone Corp. Houston, USA, ref. SEC319Hu) are expressed as ng/mL.

\subsection{Statistical Analysis}

The sample size was calculated based on the number of patients with breast cancer who started hormonal adjuvant treatment over the course of a year in the Oncology Department of the hospital Doctor Peset (Valencia) which was 77 patients in 2018. The sample size of the study population was calculated and estimated using two series model correlation tests with $G^{*}$ Power 3.1.9.2 software (G*Power@, Dusseldorf, Germany). A moderate correlation coefficient of $\mathrm{r}=0.4$; a two-tailed hypothesis; an error of $\alpha=0.05$, with a confidence interval of $95 \%$ and $\beta$ error $=20 \%$, and power analysis of $1-\beta=0.80$ were also considered Since correlation coefficient values below 0.3 are considered to be weak, $0.3-0.7$ are moderate and $>0.7$ are strong $[45,46]$, in order to calculate sample size, we assumed a moderate value of the coefficient correlation of 0.4 . A sample size of at least 44 individuals was therefore considered appropriate for this study. For the descriptive statistics, we calculated the frequency distribution for the descriptive study of the qualitative variables. For the quantitative (discrete) variables, we obtained measures of central tendency (arithmetic mean), dispersion (standard deviation (SD) and the range of values. For the bivariate analysis, we categorized patients into two groups: robust (no frailty criteria) and prefrail/frail patients (patients fulfilling at least one frailty criteria); we used non-parametric tests (U-Mann Whitman-Whitney U-test). Spearman's correlation was used for the analysis of two quantitative (discrete) variables. The statistical relationship between two categorical variables was studied by means of Pearson's Chi-square test. A logistic regression analysis was used to try to make a predictive model in order to determine associations with the variables identified in bivariate analyses by controlling for other potential confounding variables. Logistic regression can be used to evaluate several factors simultaneously that are presumably related in some way (or not) to the dependent variable (presence or not of frailty criteria). The logistic regression analysis makes it possible to obtain measures of association (odds ratio) for each variable adjusted for the others and to detect possible interactions between them and the effect studied. The significantly different discrimination accuracy of the predictive model for the biomarkers between robust and prefrail/frail patients was calculated using C-statistics (the area under the receiver operating characteristic curve; AUC). The confidence level used for all the statistics was 95\%, with a statistical significance $(p)<0.05$. The data were analyzed using the IBM SPSS Statistics $24^{\circledR}$ program. 


\section{Results}

\subsection{Sociodemographic and Clinical Data}

The sociodemographic data, clinical data related to breast cancer and comorbidity burden are summarized in Table 1. Forty-seven oncological patients were included, who were those who presented a TMN staging with a local stage I (2.1\%), early regional stage II $(72.1 \%)$ or late regional stage III $(25.5 \%)$, with lymph node involvement and without the presence of distant metastasis, for which they received treatment with either conservative surgery $(91.6 \%)$ or mastectomy $(8.4 \%)$, as well as previous chemotherapy or radiotherapy (Table 1). Regarding the patients that received previous chemotherapy, the regimens were four patients who were treated with a chemotherapy schedule consisting of 4 cycles of chemotherapy based on doxorubicin $\left(60 \mathrm{mg} / \mathrm{m}^{2}\right)$ - cyclophosphamide $\left(600 \mathrm{mg} / \mathrm{m}^{2}\right) \mathrm{ev}$ ery 3 weeks and 12 weekly cycles of paclitaxel $\left(80 \mathrm{mg} / \mathrm{m}^{2}\right)$ [47,48]. Two patients were treated with liposomal doxorubicin $\left(60 \mathrm{mg} / \mathrm{m}^{2}\right)$ —cyclophosphamide $\left(600 \mathrm{mg} / \mathrm{m}^{2}\right)$ every 21 days [49]. The adjuvant chemotherapy regimen consisting of four cycles of docetaxel $\left(75 \mathrm{mg} / \mathrm{m}^{2}\right)$ and cyclophosphamide $\left(600 \mathrm{mg} / \mathrm{m}^{2}\right)$ administered every 3 weeks was performed in the remaining 2 patients [50]. Treatment with an anti-Her2 antibody was initiated in patients with HER2+ histology (four patients): two patients received trastuzumab $(8 \mathrm{mg} / \mathrm{kg}$ initially and subsequently $6 \mathrm{mg} / \mathrm{kg}$ ) and the other two received pertuzumab (840 $\mathrm{mg}$ initially and subsequently $420 \mathrm{mg}$ ) once every 3 weeks [51,52].

Table 1. Sociodemographic and clinical characteristics.

\begin{tabular}{|c|c|}
\hline Variables & $\begin{array}{c}\text { Frequency \% (Categorical Variables) or Mean } \\
\text { and Standard Error of the Mean (Range } \\
\text { Min-Max) (Discrete Variables) }\end{array}$ \\
\hline Age (years) & $66.8 \pm 1.3(52-83)$ \\
\hline \multicolumn{2}{|l|}{ Marital status: } \\
\hline Married & $23(48.9 \%)$ \\
\hline Divorced & $7(14.9 \%)$ \\
\hline Separated & $2(4.3 \%)$ \\
\hline Single & $4(8.5 \%)$ \\
\hline Widow & $11(24.4 \%)$ \\
\hline \multicolumn{2}{|l|}{ Histology of tumor: } \\
\hline Ductal carcinoma & $46(97.9 \%)$ \\
\hline Lobular carcinoma & $1(2.1 \%)$ \\
\hline Estrogen receptor staining (\%) & $93.1 \pm 1.6(40-100)$ \\
\hline Progesterone receptor staining (\%) & $61.3 \pm 0.09(1-3)$ \\
\hline $\begin{array}{l}\text { HER2-positive staining (patients with } 3+ \\
\text { staining in HER2: } 4 \text { patients) }\end{array}$ & $2.5 \pm 5.2(0-10)$ \\
\hline Ki67 mean values (\%) & $15.4 \pm 2.03(1-60)$ \\
\hline \multicolumn{2}{|l|}{ Previous chemotherapy } \\
\hline Yes & $8(17.0 \%)$ \\
\hline No & $39(83.0 \%)$ \\
\hline \multicolumn{2}{|l|}{ Previous radiotherapy } \\
\hline Yes & $44(93.6 \%)$ \\
\hline No & $3(6.4 \%)$ \\
\hline Charlson comorbidity index & $2.5 \pm 0.1(2-5)$ \\
\hline Body mass index & $28.9 \pm 0.8(18.7-45)$ \\
\hline
\end{tabular}

The mean age of the participants was $66.8 \pm 1.3$ (SEM) (age range $52-83$ years), and all were community-dwelling women. As for marital status, they were married $(48.9 \%)$, divorced $(14.9 \%)$, separated $(4.3 \%)$, single $(8.5 \%)$ and widowed $(24.4 \%)$. Regarding histology analyses, most of the patients had a ductal carcinoma $(97.9 \%)$ and papillary carcinoma $(2.1 \%)$. For estrogen hormone receptor staining, they presented a mean of 
$93.1 \pm 1.6$ (SEM) (range 40-100) and progestogen of $62.5 \pm 5.2(0-100)$, and only 2 patients presented as HER2 positive with a mean of $1.3 \pm 0.09$ (SEM) (range 1-3). The value of the proliferation marker Ki67 indicated a mean of $15.4 \pm 2.03$ (SEM) (range 1-60), i.e., they presented proliferative activity. As for the number of daily drugs, the table shows a mean of $3.2 \pm 0.3$ (range $0-11$ ). The Charlson index adjusted for age indicated a mean index of $2.5 \pm 0.1$ (SEM) (range 2-5). The mean BMI of the participants was $28.9 \pm 0.8$ (SEM) (range $18.7-45)$. A total of $68.1 \%$ had received previous chemotherapy treatment, while $31.9 \%$ had not. However, most of the patients had received previous radiotherapy treatment (93.6\%).

\subsection{Evaluation of Frailty Syndrome}

The mean number of fulfilled frailty criteria in the sample was $0.96 \pm 0.12$ (SEM) (range 0 to 3). The frequency of each of the five criteria is specified in Table 2. Fifteen women did not fulfil any criteria for frailty syndrome (31.9\%), $21(44.7 \%)$ fulfilled one frailty criterion, nine (19.1\%) fulfilled two frailty criteria and two women (4.3\%) fulfilled three frailty criteria. Based on Fried's criteria (see Methods Section 2.3. Assessment of frailty syndrome), $31.9 \%$ of women were robust, $63.8 \%$ were pre-frail and $4.3 \%$ frail. Since the category of frail women was very small $(\mathrm{N}=2)$ we pooled together prefrail and frail women in one group, and we called it the "prefrail/frail" group.

Table 2. Criteria of frailty syndrome and geriatric assessment.

\begin{tabular}{cc}
\hline & Prevalence (\%)/Mean \pm SEM \\
\hline Frailty criterion: Involuntary weight loss & Yes $11(23.4 \%)$ \\
Frailty criterion: Weakness & No $36(76.6 \%)$ \\
\hline Frailty criterion: Low physical activity & No $42(10.7 \%)$ \\
\hline Frailty criterion: Slow gait speed & Yes $15(31.9 \%)$ \\
\hline Frailty criterion: Low muscle strength & No 32 (68.1\%) \\
\hline Cognitive functions & Yes 4 (8.5\%) \\
\hline Activities of daily living (Barthel index) & No 43 (91.5\%) \\
\hline Insomnia symptoms (Athens scale) & No 37 (78.7\%) \\
\hline Depressive symptoms (Geriatric Depression Scale) & $28.3 \pm 0.31($ range 22-30) \\
\hline Nutritional assessment (MNA scale) & $97.8 \pm 0.5($ range 90-100) \\
\hline
\end{tabular}

\subsection{Evaluation of the Frailty Score and Socio-Demographic and Clinical Variables}

There were no statistically significant differences in the age of women between the two groups ( $p=0.86$, Kruskal-Wallis test) nor any correlation between age and the frailty score (Rho $=-0.109, p=0.467$, Spearman correlation test). There were no differences in the frailty score according to the civil status of the patients ( $p=0.317$, Kruskal-Wallis test). Frailty syndrome was not associated with the type of surgery $(p=0.128$, Mann-Whitney test), nor with having received previous chemotherapy or not $(p=0.531)$. No significant correlations were found between the number of frailty criteria and staining for estrogens, progesterone or HER-2 and Ki67 in the histological analysis of breast tumors ( $p>0.05$ in all cases, Spearman correlation test). The values of Ki $67 \%$ were significantly and inversely correlated with the age of patients (Rho $=-0.303, p=0.043$, Spearman correlation test).

There was no significant correlation between the frailty criteria and the Charlson index scale (Rho $=0.126, p=0.398$, Spearman correlation), the number of daily prescribed drugs (Rho $=0.112, p=0.453$, Spearman correlation), the Barthel index (Rho $=-0.092, p=0.544$, Spearman correlation), depressive symptoms (Rho $=0.215, p=0.147$, Spearman correlation) 
or insomnia symptoms (Rho $=0.015, p=0.942$, Spearman correlation). In contrast, there was a significant inverse correlation between the frailty score and cognitive function (Rho $=-0.314, p=0.033$, Spearman correlation). There were no significant correlations between frailty syndrome and nutritional assessment (Rho $=-0113, p=0.451$, Spearman correlation) or anthropometric measurements.

\subsection{Frailty Syndrome and the Concentration of Androgens and Estrogens and the Aromatase Activity Index in the Blood}

There were significant ( $p<0.05$, Mann-Whitney test) differences between hormone concentrations in the blood between women fulfilling at least one frail criteria ("prefrail/frail" group) $(\mathrm{N}=32)$ and those who were robust $(\mathrm{N}=15)$ for FSH, $\mathrm{LH}$, estrone concentration and the aromatase activity index in the blood. In contrast, no significant differences were observed for the concentration of progesterone, estradiol testosterone, dehydroepiandrosterone, androstenedione and dihydrotestosterone (Table 3).

Table 3. Analysis of gonadotropins, androgens and estrogens concentrations and the aromatase activity index in the blood in prefrail/frail and non-frail patients. The significant $(p<0.05)$ differences between the two groups are shown in bold. "Robust" women $(\mathrm{N}=15)$ did not fulfil any frailty criteria, and "prefrail/frail" ( $\mathrm{N}=32)$ was based on Fried's classification of physical phenotype of frailty syndrome [9] (see also Methods Section 2.3. Assessment of frailty syndrome).

\begin{tabular}{|c|c|c|c|c|}
\hline Hormones in Blood & $\begin{array}{c}\text { Robust Patients } \\
\text { (Mean } \pm \text { Standard } \\
\text { Deviation) }\end{array}$ & $\begin{array}{c}\text { Prefrail/Frail Patients } \\
\text { (Mean } \pm \text { Standard } \\
\text { Deviation) }\end{array}$ & $p$ Values & $\begin{array}{l}\text { Effect Size } \\
\text { (Cohen's d) }\end{array}$ \\
\hline FSH (mUI/mL) & $43.6 \pm 5.05$ & $186.2 \pm 48.2$ & 0.013 & -0.628 \\
\hline $\mathrm{LH}(\mathrm{mUI} / \mathrm{mL})$ & $17.9 \pm 2.2$ & $79.03 \pm 19.7$ & 0.014 & -0.658 \\
\hline Progesterone (ng/mL) & $0.07 \pm 0.01$ & $0.07 \pm 0.005$ & 0.7 & 0.003 \\
\hline Estrone $(\mathrm{pg} / \mathrm{mL})$ & $24.9 \pm 2.28$ & $34.3 \pm 2.5$ & 0.02 & -0.72 \\
\hline Estradiol (pg/mL) & $7.33 \pm 0.9$ & $7.68 \pm 1.1$ & 0.60 & -0.062 \\
\hline Testosterone (ng/mL) & $0.21 \pm 0.02$ & $0.30 \pm 0.03$ & 0.06 & -0.548 \\
\hline Dehydroepiandrosterone (ug/dL) & $103.2 \pm 15.5$ & $87.2 \pm 9.54$ & 0.50 & 0.285 \\
\hline Androstenedione (pg/mL) & $123.8 \pm 12.9$ & $101.2 \pm 11.6$ & 0.15 & 0.367 \\
\hline Dihydrotestosterone (ng/mL) & $0.151 \pm 0.02$ & $0.13 \pm 0.01$ & 0.54 & 0.271 \\
\hline Aromatase activity index & $39.1 \pm 4.6$ & $31.4 \pm 5.4$ & 0.03 & 0.278 \\
\hline
\end{tabular}

There was a significant direct correlation between frailty score and the blood concentration of FSH (Rho $=0.348, p=0.017$, Spearman correlation), LH (Rho $=0.012, p=0.014$, Spearman correlation) and estrone (Rho $=0.018, p=0.020$, Spearman correlation) but no significant correlations with the other hormones. By categorizing patients as robust (0 frailty criteria) or prefrail/frail (with one or more frailty criteria), the concentration of FSH, LH and estrone was significantly higher in the prefrail/frail group compared to the robust group (Figure 1A-C). There was no significant correlation between the number of frailty criteria and the concentration of the hormone estradiol, which was detected only in 12 out of 47 women ( $26.1 \%$ of the sample), and in these patients, it was not significantly correlated with the frailty syndrome score (Rho $=0.223 ; p=0.485$, Spearman correlation). The estradiol concentration may or may not be present in postmenopausal women.

There was a significant direct correction between the frailty score and the aromatase activity index in the blood (Rho $=0.479, p=0.013$, Spearman correlation) (Figure 2A). When categorizing patients as robust ( 0 frailty criteria) and prefrail/frail (with one or more frailty criteria), the aromatase activity index was significantly higher in prefrail/frail compared to robust women ( $p=0.002$, Mann-Whitney test) (Figure 2B). There were no significant differences in the concentration of aromatase in plasma between prefrail/frail and non-frail women $(p=0.611$, Mann-Whitney test; prefrail/frail women: $3.0 \pm 0.5 \mathrm{ng} / \mathrm{mL}$; non-frail: $3.4 \pm 0.7 \mathrm{ng} / \mathrm{mL})$. 

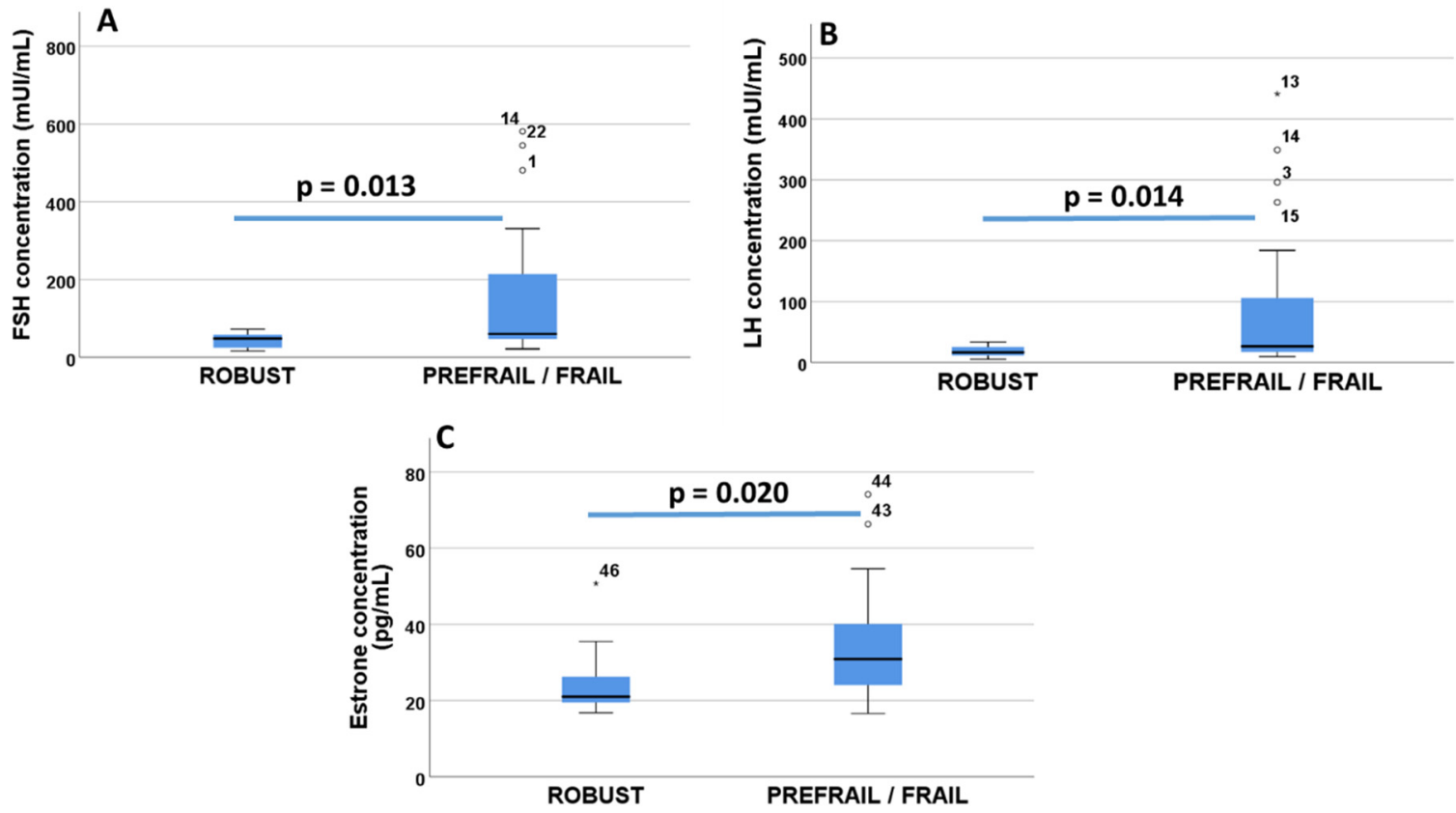

Figure 1. Differences between FSH (A), LH (B) and estrone (C) levels in non-frail (robust) and prefrail/frail women. "Robust" women $(\mathrm{N}=15)$ did not fulfil any frailty criteria and "prefrail/frail" $(\mathrm{N}=32$ ) was based on Fried's classification of physical phenotype of frailty syndrome [9] (see also Methods Section 2.3. Assessment of frailty syndrome).
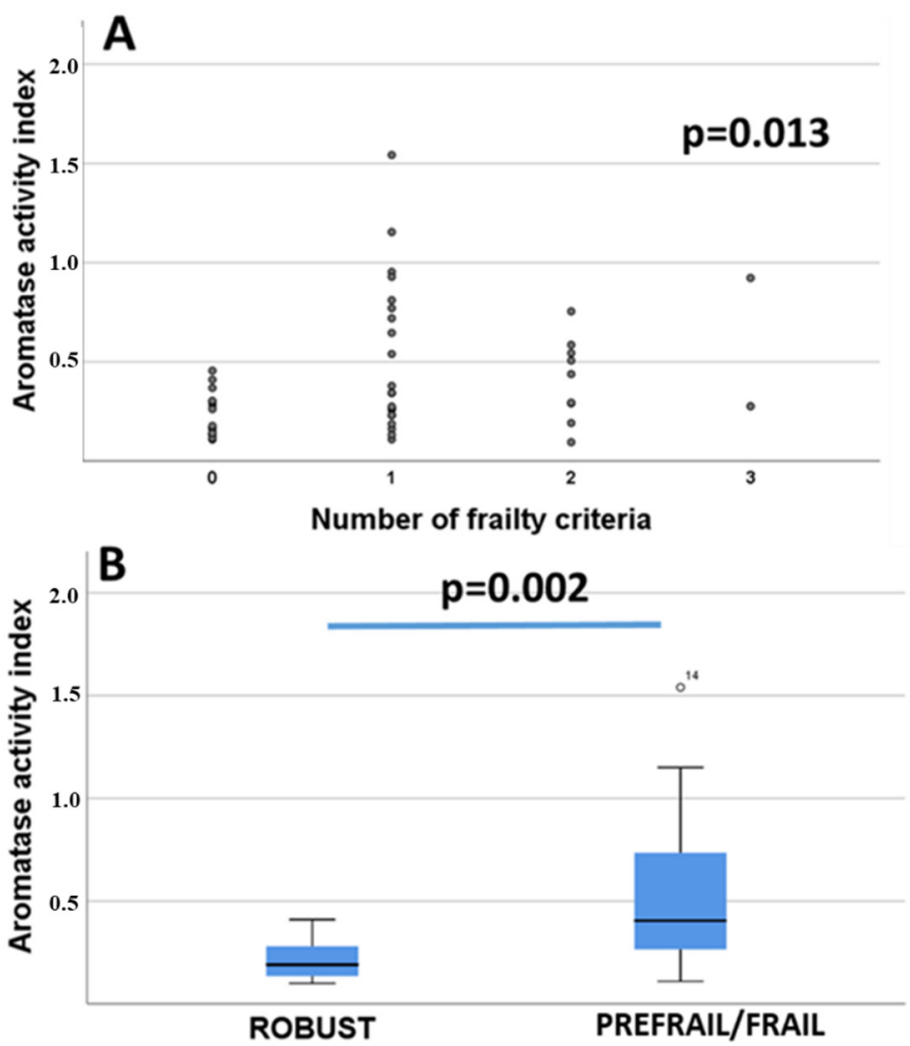

Figure 2. Aromatase activity index in non-frail (robust) and prefrail/frail women. (A): Correlation between number of fulfilled frailty criteria and aromatase activity index in blood; (B): Differences of aromatase activity index in robust and prefrail/frail patients. "Robust" women $(\mathrm{N}=15)$ did not fulfil any frailty criteria and "prefrail/frail" $(\mathrm{N}=32)$ were based on Fried's classification of physical phenotype of frailty syndrome [9] (see also Methods Section 2.3. Assessment of frailty syndrome). 
A logistic regression analysis was used to determine associations with the variables identified in the bivariate analyses by controlling for other potential confounding variables (age, previous chemotherapy treatment, Charlson comorbidity index, hormones concentration and the aromatase activity index in the blood). By selecting as the dependent variable the dichotomous variable of "presence (prefrail/frail group) or not (robust group) of any frailty criteria", we found significant effects for the aromatase activity index $(p=0.044)$, $\mathrm{OR}=0.951$ (95\% CI 0.839-0.989), and for estrone concentration ( $p=0.043), \mathrm{OR}=1.107$ (95\% CI 1.003-1.222). Other variables did not show a significant effect (Table 4).

Next, we performed a receiver operating characteristic curve (ROC) as a useful tool for evaluating the diagnostic power of these biomarkers to detect frailty syndrome categorized as robust and prefrail/frail (women fulfilling at least one criterion of frailty syndrome). This analysis provided an exhaustive look at the trend of sensitivity over all cutoffs and thus provided information about the relationship between the sensitivity and the specificity of FSH, LH and the aromatase activity index in the blood for the diagnosis of frailty (robust versus prefrail/frail patients) (Figure 3).
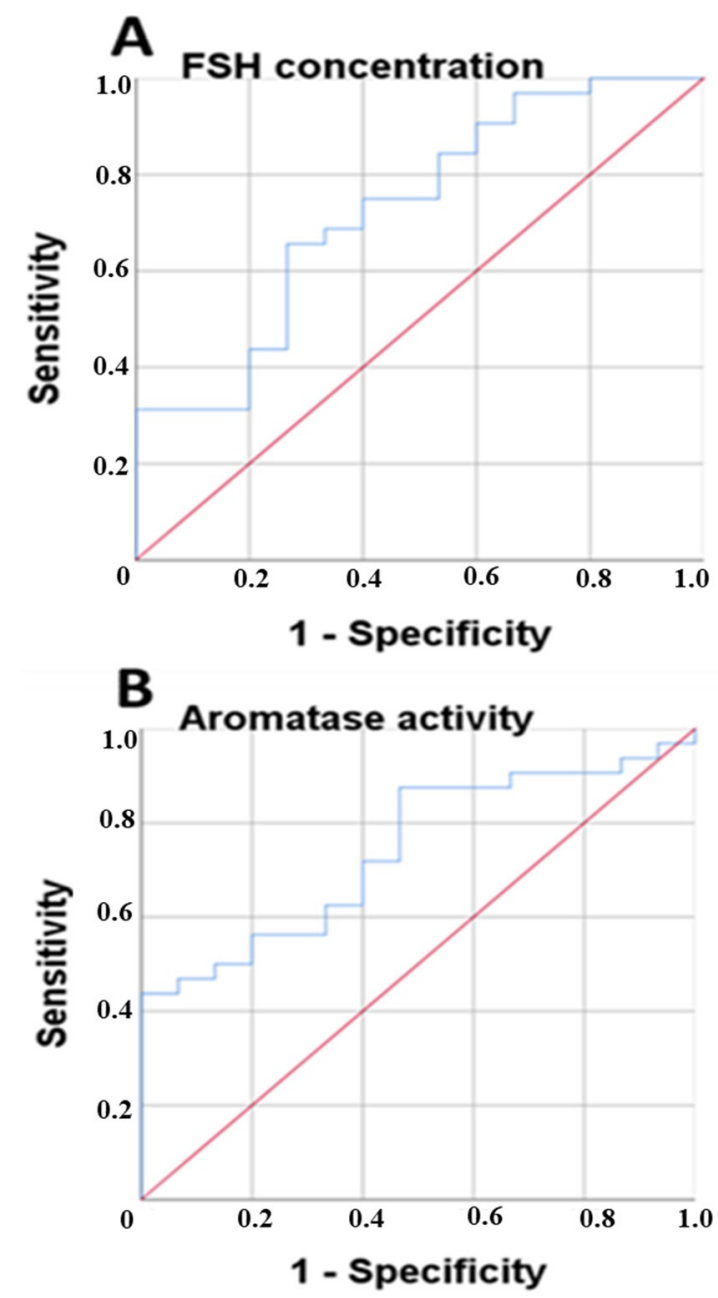

Figure 3. The receiver operating characteristic curve (ROC) for the FSH concentration in the blood (A) and the aromatase activity index in the blood (B) and the ability to discriminate between prefrail/frail and robust patients. "Robust" women $(\mathrm{N}=15)$ did not fulfil any frailty criteria and "frail" $(\mathrm{N}=32)$ was based on Fried's classification of physical phenotype of frailty syndrome [9] (see also Methods Section 2.3. Assessment of frailty syndrome). 
Table 4. Logistic regression model: variables associated with the outcome variable (presence or not of frailty criteria).

\begin{tabular}{cccc}
\hline Variables & $p$-Value & OR & 95\% IC \\
\hline Aromatase activity index & $p=0.043$ & 0.951 & $0.839-0.989$ \\
Estrone & $p=0.034$ & 1.107 & $1.003-1.222$ \\
Androstenedione & $p=0.169$ & 0.990 & $0.975-1.004$ \\
Age & $p=0.450$ & 0.964 & $0.877-1.060$ \\
FSH & $p=0.508$ & 1.017 & $0.968-1.068$ \\
LH & $p=0.657$ & 1.019 & $0.938-1.106$ \\
Previous chemotherapy treatment & $p=0.913$ & 0.867 & $0.067-11.162$ \\
Charlson comorbidity index & $p=0.657$ & 1.387 & $0.328-5.865$ \\
\hline
\end{tabular}

For the FSH concentration in the blood, the area under the curve value was 0.660 , with a $95 \%$ CI of $0.499-0.822$ (Figure $3 \mathrm{~A}$ ) with acceptable values, and the cut-off value of 55.2 had a sensitivity of $70.8 \%$ and a specificity of $39.1 \%$. For the LH concentration, the area under the curve value was 0.581 , with a $95 \% \mathrm{CI}$ of $0.414-0.747$, with the cut-off value of 22.8 , which had a sensitivity of $54.2 \%$ and a specificity of $39.1 \%$. For the estrone concentration, the area under the curve value was 0.582 , with a $95 \%$ CI of $0.416-0.747$, with a cut-off value of 23.2 , and it had a sensitivity of $75 \%$ and a specificity of $56.5 \%$. For the aromatase activity index, the area under the curve value was 0.761 , with a $95 \% \mathrm{CI}$ of $0.624-0.897$, and the cut-off value of 20.83 had a sensitivity of $87 \%$ and a specificity of $54.2 \%$.

\section{Discussion}

In our study, we identified approx. (31.9\%) one third of women as robust and not fulfilling any frailty criteria. When considering the frail group definition based on Fried's criteria (i.e., 3 or more criteria fulfilled), only $4.3 \%$ of women were frail, and the majority $(63.8 \%)$ were prefrail (i.e., one or two frailty criteria fulfilled). We pooled together prefrail and frail women in one group called "prefrail/frail", because the category of frail women was very small $(\mathrm{N}=2)$. The rate of prevalence of frailty in our study was lower compared to the data obtained for the Fried frailty syndrome prevalence ( $9.7 \%$ of frail individuals) in the community-dwelling individuals enrolled in the Cardiovascular Health Study [9]. However, the mean age of participants enrolled in the present study (mean 66.8 years old) was lower compared to the population of the Cardiovascular Health Study, which could have contributed to the low prevalence of the frail group (those fulfilling three or more frailty criteria). The prevalence of frailty has been estimated at around $6.9 \%$ in communitydwelling older adults in the United States [53], and in a population-based study in Italy, its prevalence in women aged 65 years and over was 8.8\% [54]. The Women's Health and Aging Study I-II cohort study included 786 women aged 70-79 years old reported levels of $11.3 \%$ of frailty and $43.8 \%$ of prefrailty [55]. Compared to other studies in older women, the rate of frailty was similar or lower in our sample compared to older women without cancer, probably because the mean age of the older women in the present study was lower $[56,57]$. A recent meta-analysis [58] performed in patients with stage I to IV breast cancer reported a prevalence of frailty of around $40 \%$, varying from $5 \%$ to $71 \%$ depending on the tumor stage (more frailty in advanced stages with respect to early stages of breast cancer) and the instrument used to detect frailty $[59,60]$.

The pattern of prevalence of each of the frailty criteria in older community-dwelling women in Spain has been previously described, with the most prevalent being exhaustion $(38.4 \%)$, followed by weakness $(13.9 \%)$, low physical activity $(11.8 \%)$, slow gait speed $(9.5 \%)$ and involuntary weight loss (8.9\%) [55]. In our study in women with early breast cancer, the rates and the distribution of individual frailty criterion were different as follows: low physical activity was $31.9 \%$, involuntary weight loss was $23.4 \%$, exhaustion was $21.3 \%$, weakness was $10.7 \%$ and slow gait speed was $8.5 \%$. The difference in the prevalence of the criterion of "involuntary weight loss" in breast cancer patients was significant compared to data from patients without cancer, in which this criterion of frailty was less prevalent $[9,61]$. 
Cancer is usually a traumatic experience for patients due to the various threats associated with the disease, including the diagnosis of a potentially fatal condition, complex treatment regimens, and the side effects resulting therefrom [62]. Cancer diagnosis has frequently been found to be related to psychiatric comorbidities such as depression and anxiety $[63,64]$, and weight loss has been attributed possibly as a response either to the threat associated with being diagnosed with the disease or to patho-physiological mechanisms related to cancer. A meta-analysis of cancer in primary care reported a positive association between presenting to primary care with unexpected weight loss and a subsequent diagnosis of 10 different cancers [65]. The reason of the higher prevalence of the criterion "involuntary weight loss" in our sample compared to older women without cancer could be due to the reported effects, e.g., weight loss after cancer diagnosis, which takes place even when the disease is localized and could be due to a loss of appetite due to both physical and psychological reasons [66].

Overall, the variables included in the geriatric assessment did not correlate with frailty syndrome severity (i.e., the number of frailty criteria fulfilled) except for cognitive function, and, in fact, a significant inverse correlation was observed between frailty and cognitive function (the higher frailty syndrome, the lower cognitive functions).

These data replicate previous findings about the link between physical frailty and cognitive functions $[67,68]$. In the cross-sectional study by Jürschik et al. [69], the prevalence of frailty in community-dwelling people over 75 years of age was assessed using Fried's criteria, as we used in the present study. The mean age of the participants was 81 years, and $60.3 \%$ were women. The prevalence of frailty among the participants was $9.6 \%$. Cognitive impairment was detected in $20 \%$ of the frail subjects compared to $5.3 \%$ of the robust subjects. After logistic regression, cognitive impairment was significantly associated with frailty.

Several articles have explored the effect of frailty on specific cognitive domains, with two large-scale epidemiological studies standing out. The Rush Memory and Aging Study [70], conducted in 761 individuals with a mean age of 79 years, with a mean participant education of 14.5 years, a mean MMSE score of 28.4 and in which $76 \%$ of participants were female, showed that frailty was significantly associated with global cognition and perceptual speed [71]. In our study, the subdomain related with language in the MMSE was the subdomain significantly associated with frailty syndrome. The FIBRA study analyzed the frailty status according to the CHS frailty criteria in older individuals in Brazil [72] and found that frail participants had a significant impairment as measured by the MMSE, although the association with frailty syndrome was not only with the language subdomain, but also with the orientation and immediate memory subdomains of the MMSE.

We observed significant associations between frailty syndrome severity and the gonadotropins LH and FSH, estrone and the aromatase activity index in the blood. The associations between frailty syndrome and the gonadotropins FSH and LH were not related to the age of the patients, and they still remained after taking age into account as a potential confounder, suggesting it was not related to the time elapsed since menopause or the extent of hypogonadism. However, when controlling for other variables affecting frailty syndrome (previous chemotherapy treatment and Charlson comorbidity index), the significant associations between gonadotropins in the blood and the presence or not of frailty criteria were lost. A study performed in older men also reported a consistent association between frailty and gonadotropins in the blood [21]. In fully adjusted models, higher luteinizing hormone and follicle-stimulating hormones were positively related to worsening frailty syndrome in a 4-year follow-up study only in men but not in women [73]. We found no significant differences between testosterone levels, which replicate the findings of other studies reporting similar non-significant associations in women [16,18]. Very low levels of testosterone are observed in older women with $\geq 4$ frailty criteria [16], and in our study, any women had this level of frailty, which may explain the lack of a significant association between frailty and testosterone. The association of free testosterone with frailty appeared confined to obese women [16]. Surgically, menopausal women had significantly lower total serum testosterone levels than naturally menopausal women, although they were not at a 
greater risk of frailty or death after adjusting for age, body mass index and the number of impaired instrumental activities of daily living [74].

Our study has been the first to report hormonal biomarkers as associated with prefrailty/frailty in post-menopausal women with breast cancer. The concentrations of FSH and LH show a moderate sensitivity and specificity to discriminate robust versus prefrail/frail women in our study, and it replicates the finding obtained in men [21,75]. The concentration of estrone, the major estrogen in post-menopausal women, was significantly increased in prefrail/frail women compared to robust ones. These data agree with other reports which showed higher estradiol associated with a higher degree of frailty syndrome [16] and higher estradiol in the blood, predicting a lower likelihood of improving frailty syndrome over time [73]. Consistent with our results, Schaap et al. [76] suggested a possible although not a significant association of higher estradiol in women included in the Longitudinal Aging Study Amsterdam. They also reported that women with high serum levels of estradiol had a higher rate of functional limitations. The lack of significance in their analyses could be due to a differential effect of estradiol on muscle strength and physical performance according to age, which they did not identify. Finally, another observational study reported no association between estrone, the primary estrogen present in postmenopausal women, and muscle mass and strength with poor physical performance and low muscle strength [77].

The increase in the estrogen concentration in the blood in frail postmenopausal women in the Toledo Study for Healthy Aging older was significantly associated with the highsensitivity C-reactive protein concentration in the blood, suggesting the existence of physiopathological mechanisms connecting inflammation and estrogen concentration to frailty syndrome [16]. Confirming the results of the Toledo Study for Healthy Aging, our study also found that prefrail/frail women had increased estrone levels in the blood. Aromatase is a cytochrome p450 enzyme encoded by the CYP19A1 gene that converts androgens to estrogens and specifically converts testosterone and androstenedione to aromatic estrogens, estradiol and estrone, respectively [78]. Aromatase-facilitated estrogen production mainly occurs in the ovaries of premenopausal women, whereas in postmenopausal women, it takes place in peripheral tissues and especially in adipose tissue. Our study has been the first to report that an increase in the aromatase activity index (but not its concentration in plasma) is associated with frailty syndrome in post-menopausal women, with a reduction of the activity index in non-frail women compared to prefrail/frail ones, which goes in parallel with the changes observed in estrone (the product formed by its enzymatic activity). Among the biomarkers associated with frailty syndrome in breast cancer patients, the best profile is represented by the aromatase activity index, which showed a good sensitivity of $87 \%$ and a moderate specificity of $54.2 \%$ to discriminate between frail and non-frail patients. However, we must be cautious when interpreting the aromatase activity index as a biomarker of prefrailty/frailty in post-menopausal women until longitudinal studies are performed. In addition, we cannot exclude that the changes observed in hormone levels and the aromatase activity index may or may not be directly related to the development of frailty; there may be some intermediary factors, including inflammatory [79-81] and stress markers [82,83]. In fact, even in individuals with a low grade of frailty syndrome, such as prefrail individuals based on Fried's criteria, frailty syndrome is associated with an increase in some peripheral inflammatory factors [84], and this aspect needs to be evaluated in postmenopausal women with breast cancer. In our study, most participants were prefrail based on the physical phenotype of Fried's definition of frailty, e.g., they fulfilled one or two criteria of frailty, and future studies need to evaluate frailty syndrome in a population of women with breast cancer with higher odds of frailty. The fact that the presence of some of frailty criteria (prefrailty) is associated with a reduction in aromatase activity suggests that, as the first-line adjuvant treatment in post-menopausal women with breast cancer, aromatase inhibitor treatments may worsen frailty syndrome in these women. It should be pointed out that frailty syndrome based on Fried's criteria, being composed of very general signs or symptoms, raises an "alert" about a possible problem related to increased vulnerability to 
stressors and a decrease in the physiological reserve. Appropriate therapeutic strategies, recommended in order to minimize the impact of frailty on the health of older woman with cancer, should start only after a comprehensive geriatric assessment that is capable of providing the required information supporting specific actions. The present study has some important limitations. First, the sample size was relatively small for a prevalent cancer, such as breast cancer. However, considering that the study was based on a single hospital center, the sample size was calculated based on the total number of patients with breast cancer $(\mathrm{N}=77)$ who started hormonal adjuvant treatment over the course of a year; we think that a sample of 47 patients is quite acceptable for representing patients in our clinical context. Nevertheless, in our opinion, the study suggests future lines of research in this field of geriatric oncology. Second, although frailty has been conceptualized as a multidimensional geriatric syndrome, we evaluated it using the criteria proposed by Fried et al. [9], which are closely linked to physical condition. However, from our point of view these criteria have several advantages that make them suitable for the clinical setting, since they are objective, brief and easy to use [85]. The influence of previous chemotherapy regimens, however, did not show any significant difference in the study's outcomes; we cannot rule out that enrolling a higher number of patients with previous chemotherapy could have led to some differences in the frailty syndrome or hormone measurements. Finally, the cross-sectional design of the study prevented us from evaluating the causality of the identified associations between prefrailty / frailty and inflammatory markers, and it did not allow us to rule out the possibility that these associations may be due to non-causal relationships.

\section{Conclusions}

The results of our study provide new evidence linking the presence of prefrailty / frailty in women with breast cancer to the alteration of hormonal changes in the blood and the aromatase activity index. In clinical practice, the identification of biomarkers, if confirmed in longitudinal studies, could be helpful in the early identification of post-menopausal women with breast cancer who are at risk of becoming prefrail or frail. These individuals would benefit from a comprehensive integral geriatric assessment, and treatment of the individual patient should be based on their health status regardimg frailty syndrome, according to the new directions in this field [86-88].

Author Contributions: Conceptualization J.G.-S., M.D.T. and O.C.; methodology J.G.-S., M.D.T. and O.C.; formal analysis, J.G.-S. and M.A.M.-E.; investigation: J.G.-S., M.A.M.-E., C.T.-C., O.A.-C., M.D.T. and O.C.; writing-original draft preparation, J.G.-S., M.A.M.-E., M.D.T. and O.C.; writing-review and editing J.G.-S., M.A.M.-E., M.D.T. and O.C. All authors have read and agreed to the published version of the manuscript.

Funding: This research was funded by the University of Valencia, grant number UV-19-INV_AE19.

Institutional Review Board Statement: The study was conducted in accordance with the Declaration of Helsinki, and it was approved by the Ethics Committee of University Hospital Peset (Valencia, Spain) (protocol code 57/18, date of approval: 25 July 2018).

Informed Consent Statement: Informed consent was obtained from all subjects involved in the study.

Data Availability Statement: The data presented in this study are available on request from the corresponding author for scientific purposes.

Conflicts of Interest: The authors declare no conflict of interest.

\section{References}

1. Li, X.; Oprea-Ilies, G.M.; Krishnamurti, U. New developments in breast cancer and their impact on daily practice in pathology. Arch. Pathol. Lab. Med. 2017, 141, 490-498. [CrossRef] [PubMed]

2. Mattiuzzi, C.; Lippi, G. Current cancer epidemiology. J. Epidemiol. Glob. Health 2019, 9, 217-222. [CrossRef] [PubMed]

3. Ferrando, J.; Palència, L.; Gotsens, M.; Puig-Barrachina, V.; Marí-Dell'Olmo, M.; Rodríguez-Sanz, M.; Bartoll, X.; Borrell, C. Trends in cancer mortality in Spain: The influence of the financial crisis. Gac. Sanit. 2019, 33, 229-234. [CrossRef] [PubMed] 
4. Zhang, X.; Meng, X.; Chen, Y.; Leng, S.X.; Zhang, H. The biology of aging and cancer: Frailty, inflammation, and immunity. Cancer J. 2017, 23, 201-205. [CrossRef] [PubMed]

5. Cesari, M.; Calvani, R.; Marzetti, E. Frailty in older persons. Clin. Geriatr. Med. 2017, 33, 293-303. [CrossRef] [PubMed]

6. Fried, L.P.; Ferrucci, L.; Darer, J.; Williamson, J.D.; Anderson, G. Untangling the concepts of disability, frailty, and comorbidity: Implications for improved targeting and care. J. Gerontol. A Biol. Sci. Med. Sci. 2004, 59, 255-263. [CrossRef]

7. Wilson, D.; Jackson, T.; Sapey, E.; Lord, J.M. Frailty and sarcopenia: The potential role of an aged immune system. Ageing Res. Rev. 2017, 36, 1-10. [CrossRef]

8. Wildiers, H.; Heeren, P.; Puts, M.; Topinkova, E.; Janssen-Heijnen, M.L.; Extermann, M.; Falandry, C.; Artz, A.; Brain, E.; Colloca, G.; et al. International Society of Geriatric Oncology consensus on geriatric older patients with cancer. J. Clin. Oncol. 2014, 32, 2595-2603. [CrossRef]

9. $\quad$ Fried, L.P.; Tangen, C.M.; Walston, J.; Newman, A.B.; Hirsch, C.; Gottdiener, J.; Seeman, T.; Tracy, R.; Kop, W.J.; Burke, G.; et al Frailty in older adults: Evidence for a phenotype. J. Gerontol. A Biol. Sci. Med. Sci. 2001, 56, M146-M156. [CrossRef]

10. Ruan, H.; Hu, J.; Zhao, J.; Tao, H.; Chi, J.; Niu, X.; Zhang, J.; Wang, Y. Menopause and frailty: A scoping review. Menopause 2020, 27, 1185-1195. [CrossRef]

11. Walston, J.; Fried, L.P. Frailty and the older man. Med. Clin. N. Am. 1999, 83, 1173-1194. [CrossRef]

12. Poehlman, E.T.; Toth, M.J.; Fishman, P.S.; Vaitkevicius, P.; Gottlieb, S.S.; Fisher, M.L.; Fonong, T. Sarcopenia in aging humans: The impact of menopause and disease. J. Gerontol. A Biol. Sci. Med. 1995, 50, 73-77.

13. Wu, I.C.; Lin, X.Z.; Liu, P.F.; Tsai, W.L.; Shiesh, S.C. Low serum testosterone and frailty in older men and women. Maturitas 2010, 67, 348-352. [CrossRef] [PubMed]

14. Mohr, B.A.; Bhasin, S.; Kupelian, V.; Araujo, A.B.; O’Donnell, A.B.; McKinlay, J.B. Testosterone, sex hormone-binding globulin, and frailty in older men. J. Am. Geriatr. Soc. 2007, 55, 548-555. [CrossRef]

15. O'Donnell, A.B.; Araujo, A.B.; McKinlay, J.B. The health of normally aging men: The Massachusetts Male Aging Study (1987-2004). Exp. Gerontol. 2004, 39, 975-984. [CrossRef]

16. Carcaillon, L.; García-García, F.J.; Tresguerres, J.A.F.; Guitiérrez Avila, G.; Kireev, R.; Rodríguez-Mañas, L. Higher levels of endrogenous estradiol are associated with frailty in postmenpausal women from the Toledo study for healthy aging. J. Clin. Endorinol. Metab. 2012, 97, 2898-2906. [CrossRef]

17. Orentreich, N.; Brind, J.L.; Rizer, R.L.; Vogelman, J.H. Age changes and sex differences in serum dehydroepiandrosterone sulfate concentrations throughout adulthood. J. Clin. Endocrinol. Metab. 1984, 59, 551-555. [CrossRef]

18. Cappola, A.R.; Xue, Q.L.; Fried, L.P. Multiple hormonal deficiencies in anabolic hormones are found in frail older women: The Women's Health and Aging studies. J. Gerontol. A Biol. Sci. Med. Sci. 2009, 64, 243-248. [CrossRef]

19. Leng, S.X.; Cappola, A.R.; Andersen, R.E.; Blackman, M.R.; Koenig, K.; Blair, M.; Walston, J.D. Serum levels of insulin-like growth factor-I (IGF-I) and dehydroepiandrosterone sulfate (DHEA-S), and their relationships with serum interleukin-6, in the geriatric syndrome of frailty. Aging Clin. Exp. Res. 2004, 16, 153-157. [CrossRef]

20. Cawthon, P.M.; Ensrud, K.E.; Laughlin, G.A.; Cauley, J.A.; Dam, T.T.; Barrett-Connor, E.; Fink, H.A.; Hoffman, A.R.; Lau, E.; Lane, N.E.; et al. Sex hormones and frailty in older men: The osteoporotic fractures in men (MrOS) study. J. Clin. Endocrinol. Metab. 2009, 94, 3806-3815. [CrossRef]

21. Travison, T.G.; Nguyen, A.H.; Naganathan, V.; Stanaway, F.F.; Blyth, F.M.; Cumming, R.G.; Le Couteur, D.G.; Sambrook, P.N.; Handelsman, D.J. Changes in reproductive hormone concentrations predict the prevalence and progression of the frailty syndrome in older men: The concord health and ageing in men project. J. Clin. Endocrinol. Metab. 2011, 96, 2464-2474. [CrossRef] [PubMed]

22. Eichholzer, M.; Barbir, A.; Basaria, S.; Dobs, A.S.; Feinleib, M.; Guallar, E.; Menke, A.; Nelson, W.G.; Rifai, N.; Platz, E.A.; et al Serum sex steroid hormones and frailty in older American men of the Third National Health and Nutrition Examination Survey (NHANES III). Aging Male 2012, 15, 208-215. [CrossRef] [PubMed]

23. Bellieni, A.; Fusco, D.; Sanchez, A.M.; Franceschini, G.; Di Capua, B.; Allocca, E.; Di Stasio, E.; Marazzi, F.; Tagliaferri, L.; Masetti, R.; et al. Different impact of definitions of sarcopenia in defining frailty status in a population of older women with early breast cancer. J. Pers. Med. 2021, 11, 243. [CrossRef] [PubMed]

24. Horstman, A.M.; Dillon, E.L.; Urban, R.J.; Sheffield-Moore, M. The role of androgens and estrogens on healthy aging and longevity. J. Gerontol. A Biol. Sci. Med. Sci. 2012, 67, 1140-1152. [CrossRef]

25. Almeida, M.; Laurent, M.R.; Dubois, V.; Claessens, F.; O’Brien, C.A.; Bouillon, R.; Vanderschueren, D.; Manolagas, S.C. Estrogens and androgens in skeletal physiology and pathophysiology. Physiol. Rev. 2017, 97, 135-187. [CrossRef]

26. Li, J.J.; Shao, Z.M. Endocrine therapy as adjuvant or neoadjuvant therapy for breast cancer: Selecting the best agents, the timing and duration of treatment. Chin. Clin. Oncol. 2016, 5, 40. [CrossRef]

27. Fernández-Garrido, J.; Navarro-Martínez, R.; Buigues-González, C.; Martínez-Martínez, M.; Ruiz-Ros, V.; Cauli, O. The value of neutrophil and lymphocyte count in frail older women. Exp. Gerontol. 2014, 54, 35-41. [CrossRef]

28. Orme, J.G.; Reis, J.; Herz, E.J. Factorial and discriminant validity of the Center for Epidemiological Studies Depression (CES-D) scale. J. Clin. Psychol. 1986, 42, 28-33. [CrossRef]

29. Rubio Castañeda, F.J.; Tomás Aznar, C.; Muro Baquero, C. Medición de la actividad física en personas mayores de 65 años mediante el IPAQ-E: Validez de contenido, fiabilidad y factores asociados [Validity, Reliability and Associated Factors of the International Physical Activity Questionnaire Adapted to Elderly (IPAQ-E)]. Rev. Esp. Salud Publica 2017, 18, 91. 
30. Treacy, D.; Hassett, L. The short physical performance battery. J. Physiother. 2018, 64, 61. [CrossRef]

31. Graham, J.E.; Ostir, G.V.; Fisher, S.R.; Ottenbacher, K.J. Assessing walking speed in clinical research: A systematic review. J. Eval. Clin. Pract. 2008, 14, 552-562. [CrossRef] [PubMed]

32. Lobo, A.; Saz, P.; Marcos, G.; Día, J.L.; de la Cámara, C.; Ventura, T.; Morales Asín, F.; Fernando Pascual, L.; Montañés, J.A.; Aznar, S. Revalidación y normalización del Mini-Examen Cognoscitivo (primera versión en castellano del Mini-Mental Status Examination) en la población general geriátrica [Revalidation and standardization of the cognition mini-exam (first Spanish version of the Mini-Mental Status Examination) in the general geriatric population]. Med. Clin. 1999, 112, 767-774, Erratum in Med. Clin. 1999, 113, 197.

33. Sheikh, J.I.; Yesavage, J.A.; Brooks, J.O., III; Friedman, L.; Gratzinger, P.; Hill, R.D.; Zadeik, A.; Crook, T. Proposed factor structure of the Geriatric Depression Scale. Int. Psychogeriatr. 1991, 3, 23-28. [CrossRef]

34. Orcos, R.O.; Fort, M.S.; Khajoui, A.K.; Aparicio, S.V.; Del Valle, R.D.D. Validación de la versión española de 5 y 15 ítems de la Escala de Depresión Geriátrica en personas mayores en Atención Primaria [Validation of 5 and 15 items Spanish version of the geriatric depression scale in elderly subjects in primary health care setting]. Rev. Clin. Esp. 2007, 207, 559-562.

35. González, N.; Bilbao, A.; Forjaz, M.J.; Ayala, A.; Orive, M.; Garcia-Gutierrez, S.; Hayas, C.L.; Quintana, J.M.; OFF (Older Falls Fracture)-IRYSS group. Psychometric characteristics of the Spanish version of the Barthel Index. Aging Clin. Exp. Res. 2018, 30, 489-497. [CrossRef] [PubMed]

36. Kondrup, J.; Allison, S.P.; Elia, M.; Vellas, B.; Plauth, M.; Educational and Clinical Practice Committee; European Society of Parenteral and Enteral Nutrition (ESPEN). ESPEN guidelines for nutrition screening 2002. Clin. Nutr. 2003, 22, 415-421. [CrossRef]

37. Winter, J.E.; MacInnis, R.J.; Nowson, C.A. The influence of age on the BMI and all-cause mortality association: A meta-analysis. J. Nutr. Health Aging 2017, 21, 1254-1258. [CrossRef]

38. Setiati, S.; Istanti, R.; Andayani, R.; Kuswardhani, R.A.; Aryana, I.G.; Putu, I.D.; Apandi, M.; Ichwani, J.; Soewoto, S.; Dinda, R.; et al. Cut-off of anthropometry measurement and nutritional status among elderly outpatient in Indonesia: Multi-centre study. Acta Med. Indones. 2010, 42, 224-230.

39. Heim, N.; Snijder, M.B.; Heymans, M.W.; Deeg, D.J.; Seidell, J.C.; Visser, M. Optimal cutoff values for high-risk waist circumference in older adults based on related health outcomes. Am. J. Epidemiol. 2011, 174, 479-489. [CrossRef]

40. Gómez-Benito, J.; Ruiz, C.; Guilera, G. A Spanish version of the Athens Insomnia Scale. Qual. Life Res. 2011, 20, 931-937. [CrossRef]

41. Soldatos, C.R.; Dikeos, D.G.; Paparrigopoulos, T.J. The diagnostic validity of the Athens Insomnia Scale. J. Psychosom. Res. 2003, 55, 263-267. [CrossRef]

42. Charlson, M.E.; Pompei, P.; Ales, K.L.; MacKenzie, C.R. A new method of classifying prognostic comorbidity in longitudinal studies: Development and validation. J. Chronic Dis. 1987, 40, 373-383. [CrossRef]

43. Vermeulen, A.; Deslypere, J.P.; Paridaens, R.; Leclercq, G.; Roy, F.; Heuson, J.C. Aromatase, 17 beta-hydroxysteroid dehydrogenase and intratissular sex hormone concentrations in cancerous and normal glandular breast tissue in postmenopausal women. Eur. J. Cancer Clin. Oncol. 1986, 22, 515-525. [CrossRef]

44. Newton, C.J.; Samuel, D.L.; James, V.H. Aromatase activity and concentrations of cortisol, progesterone and testosterone in breast and abdominal adipose tissue. J. Steroid Biochem. 1986, 24, 1033-1039. [CrossRef]

45. Kraemer, H.C. Correlation coefficients in medical research: From product moment correlation to the odds ratio. Stat. Methods Med. Res. 2006, 15, 525-545. [CrossRef]

46. Mukaka, M.M. Statistics corner: A guide to appropriate use of correlation coefficient in medical research. Malawi Med. J. 2012, 24, 69-71.

47. Early Breast Cancer Trialists' Collaborative Group (EBCTG); Peto, R.; Davies, C.; Godwin, J.; Gray, R.; Pan, H.C.; Clarke, M.; Cutter, D.; Dardy, S.; McGale, P.; et al. Comparisons between different poly-chemotherapy regimens for early breast cancer: Meta-analyses of long-term outcome among 100,000 women in 123 randomised trials. Lancet 2012, 379, 432-444.

48. Gianni, L.; Baselga, J.; Eiermann, W.; Porta, V.G.; Semiglazov, V.; Lluch, A.; Zambetti, M.; Sabadell, D.; Raab, G.; Cussac, A.L.; et al. Phase III trial evaluating the addition of paclitaxel to doxorubicin followed by cyclophosphamide, methotrexate, and fluorouracil, as adjuvant or primary systemic therapy: European Cooperative Trial in Operable Breast Cancer. J. Clin. Oncol. 2009, 27, 2474-2481. [CrossRef]

49. Campos, S. Liposomal anthracyclines: Adjuvant and neoadjuvant therapy for breast cancer. Oncologist 2003, 8, 10-16. [CrossRef]

50. Jones, S.; Holmes, F.A.; O'Shaughnessy, J.; Blum, J.L.; Vukelja, S.J.; McIntyre, K.J.; Pippen, J.E.; Bordelon, J.H.; Kirby, R.L.; Sandbach, J.; et al. Docetaxel with cyclophosphamide is associated with an overall survival benefit compared with doxorubicin and cyclophosphamide: 7-year follow-up of US Oncology Research Trial 9735. J. Clin. Oncol. 2009, 27, 1177-1183. [CrossRef]

51. Gianni, L.; Pienkowski, T.; Im, Y.H.; Roman, L.; Tseng, L.M.; Liu, M.C.; Lluch, A.; Staroslawska, E.; de la Haba-Rodriguez, J.; Im, S.A.; et al. Efficacy and safety of neoadjuvant pertuzumab and trastuzumab in women with locally advanced, inflammatory, or early HER2-positive breast cancer (NeoSphere): A randomised multicentre, open-label, phase 2 trial. Lancet Oncol. 2012, 13, 25-32. [CrossRef]

52. Schneeweiss, A.; Chia, S.; Hickish, T.; Harvey, V.; Eniu, A.; Hegg, R.; Tausch, C.; Seo, J.H.; Tsai, Y.F.; Ratnayake, J.; et al. Pertuzumab plus trastuzumab in combination with standard neoadjuvant anthracycline-containing and anthracycline-free chemotherapy regimens in patients with HER2-positive early breast cancer: A randomized phase II cardiac safety study (TRYPHAENA). Ann. Oncol. 2013, 24, 2278-2284. [CrossRef] [PubMed] 
53. Weiss, C.O. Frailty and chronic diseases in older adults. Clin. Geriatr. Med. 2011, 27, 39-52. [CrossRef] [PubMed]

54. Cesari, M.; Leeuwenburgh, C.; Lauretani, F.; Onder, G.; Bandinelli, S.; Maraldi, C.; Guralnik, J.M.; Pahor, M.; Ferrucci, L. Frailty syndrome and skeletal muscle: Results from the Invecchiare in Chianti study. Am. J. Clin. Nutr. 2006, 83, 1142-1148. [CrossRef] [PubMed]

55. Bandeen-Roche, K.; Xue, Q.L.; Ferrucci, L.; Walston, J.; Guralnik, J.M.; Chaves, P.; Zeger, S.L.; Fried, L.P. Phenotype of Frailty: Characterization in the women's health and aging studies. J. Gerontol. A Biol. Sci. Med. Sci. 2006, 61, 262-266. [CrossRef] [PubMed]

56. Woods, N.F.; LaCroix, A.Z.; Gray, S.L.; Aragaki, A.; Cochrane, B.B.; Brunner, R.L.; Masaki, K.; Murray, A.; Newman, A.B.; Women's Health Initiative. Frailty: Emergence and consequences in women aged 65 and older in the Women's Health Initiative Observational Study. J. Am. Geriatr. Soc. 2005, 53, 1321-1330, Erratum in J. Am. Geriatr. Soc. 2017, 65, 1631-1632. [CrossRef]

57. Santos-Eggimann, B.; Cuénoud, P.; Spagnoli, J.; Junod, J. Prevalence of frailty in middle-aged and older community-dwelling Europeans living in 10 countries. J. Gerontol. A Biol. Sci. Med. Sci. 2009, 64, 675-681. [CrossRef]

58. Wang, S.; Yang, T.; Qiang, W.; Shen, A.; Zhao, Z.; Yang, H.; Liu, X. The prevalence of frailty among breast cancer patients: A systematic review and meta-analysis. Support Care Cancer 2022, 30, 2993-3006. [CrossRef]

59. Kirkhus, L.; Šaltyte Benth, J.; Grønberg, B.H.; Hjermstad, M.J.; Rostoft, S.; Harneshaug, M.; Selbæk, G.; Wyller, T.B.; Jordhøy, M.S. Frailty identified by geriatric assessment is associated with poor functioning, high symptom burden and increased risk of physical decline in older cancer patients: Prospective observational study. Palliat. Med. 2019, 33, 312-322. [CrossRef]

60. Gilmore, N.; Kadambi, S.; Lei, L.; Loh, K.P.; Mohamed, M.; Magnuson, A.; Cole, S.; Esparaz, B.T.; Giguere, J.K.; Mohile, S.; et al. Associations of inflammation with frailty in patients with breast cancer aged 50 and over receiving chemotherapy. J. Geriatr. Oncol. 2020, 11, 423-430. [CrossRef]

61. Garcia-Garcia, F.J.; Gutierrez Avila, G.; Alfaro-Acha, A.; Amor Andres, M.S.; De Los Angeles De La Torre Lanza, M.; Escribano Aparicio, M.V.; Humanes Aparicio, S.; Larrion Zugasti, J.L.; Gomez-Serranillo Reus, M.; Rodriguez-Artalejo, F.; et al. The prevalence of frailty syndrome in an older population from Spain. The Toledo Study for Healthy Aging. J. Nutr. Health Aging 2011, 15, 852-856. [CrossRef] [PubMed]

62. Cordova, M.J.; Giese-Davis, J.; Golant, M.; Kronenwetter, C.; Vickie, C.; Spiegel, D. Breast cancer as trauma: Posttraumatic stress and posttraumatic growth. J. Clin. Psychol. Med. Settings 2007, 14, 308-319. [CrossRef]

63. Tsaras, K.; Papathanasiou, I.V.; Mitsi, D.; Veneti, A.; Kelesi, M.; Zyga, S.; Fradelos, E.C. Assessment of depression and anxiety in breast cancer patients: Prevalence and associated factors. Asian Pac. J. Cancer Prev. 2018, 19, 1661-1669. [PubMed]

64. Zhu, J.; Fang, F.; Sjölander, A.; Fall, K.; Adami, H.O.; Valdimarsdóttir, U. First-onset mental disorders after cancer diagnosis and cancer-specific mortality: A nationwide cohort study. Ann. Oncol. 2017, 28, 1964-1969. [CrossRef] [PubMed]

65. Nicholson, B.D.; Hamilton, W.; O'Sullivan, J.; Aveyard, P.; Hobbs, F.R. Weight loss as a predictor of cancer in primary care: A systematic review and meta-analysis. Br. J. Gen. Pract. 2018, 68, e311-e322. [CrossRef]

66. Jackson, S.E.; Williams, K.; Steptoe, A.; Wardle, J. The impact of a cancer diagnosis on weight change: Findings from prospective, population-based cohorts in the UK and the US. BMC Cancer 2014, 14, 926. [CrossRef]

67. Avila-Funes, J.A.; Amieva, H.; Barberger-Gateau, P.; Le Goff, M.; Raoux, N.; Ritchie, K.; Carrière, I.; Tavernier, B.; Tzourio, C.; Gutiérrez-Robledo, L.M.; et al. Cognitive impairment improves the predictive validity of the phenotype of frailty for adverse health outcomes: The Three-City Study. J. Am. Geriatr. Soc. 2009, 57, 453-461. [CrossRef]

68. Samper-Ternent, R.; Al Snih, S.; Raji, M.A.; Markides, K.S.; Ottenbacher, K.J. Relationship between frailty and cognitive decline in older Mexicans Americans. J. Am. Geriatr. Soc. 2008, 56, 1845-1852. [CrossRef]

69. Jürschik, P.; Nunin, C.; Botigue, T.; Escobar, M.A.; Lavedan, A.; Viladrosa, M. Prevalence of frailty and factors associated with frailty in the elderly population of Lleida, Spain: The FRALLE survey. Arch. Gerontol. Geriatr. 2012, 55, 625-631. [CrossRef]

70. Boyle, P.A.; Buchman, A.S.; Wilson, R.S.; Leurgans, S.E.; Bennett, D.A. Association of muscle strength with the risk of Alzheimer disease and the rate of cognitive decline in community-dwelling older persons. Arch. Neurol. 2009, 66, 1339-1344. [CrossRef]

71. Mitnitski, A.; Fallah, N.; Rockwood, K. A multistate model of cognitive dynamics in relation to frailty in older adults. Ann. Epidemiol. 2011, 21, 507-516. [CrossRef] [PubMed]

72. Yassuda, M.S.; Lopes, A.; Cachioni, M.; Falcao, D.V.; Batistoni, S.S.; Guimaraes, V.V.; Neri, A.L. Frailty criteria and cognitive performance are related: Data from the FIBRA study in Ermelino Matarazzo, São Paulo, Brazil. J. Nutr. Health Aging 2012, 16, 55-61. [CrossRef] [PubMed]

73. Swiecicka, A.; Eendebak, R.J.A.H.; Lunt, M.; O’Neill, T.W.; Bartfai, G.; Casanueva, F.F.; Forti, G.; Giwercman, A.; Han, T.S.; Slowikowska-Hilczer, J.; et al. Reproductive hormone levels predict changes in frailty status in community-dwelling older men: European Male Ageing Study Prospective Data. J. Clin. Endocrinol. Metab. 2018, 103, 701-709. [CrossRef] [PubMed]

74. Huang, G.; Coviello, A.; LaValley, M.P.; Ensrud, K.E.; Cauley, J.A.; Cawthon, P.M.; Fredman, L. Surgical menopause and frailty risk in community-dwelling older women: Study of osteoporotic fractures. J. Am. Geriatr. Soc. 2018, 66, 2172-2177. [CrossRef]

75. Tajar, A.; O'Connell, M.D.; Mitnitski, A.B.; O’Neill, T.W.; Searle, S.D.; Huhtaniemi, I.T.; Finn, J.D.; Bartfai, G.; Boonen, S.; Casanueva, F.F.; et al. Frailty in relation to variations in hormone levels of the hypothalamic-pituitary-testicular axis in older men: Results from the European male aging study. J. Am. Geriatr. Soc. 2011, 59, 814-821. [CrossRef] [PubMed]

76. Schaap, L.A.; van Schoor, N.M.; Lips, P.; Visser, M. Associations of sarcopenia definitions, and their components, with the incidence of recurrent falling and fractures: The longitudinal aging study Amsterdam. J. Gerontol. A. Biol. Sci. Med. Sci. 2018, 73, 1199-1204. [CrossRef] [PubMed] 
77. Baumgartner, R.N.; Waters, D.L.; Gallagher, D.; Morley, J.E.; Garry, P.J. Predictors of skeletal muscle mass in elderly men and women. Mech. Ageing Dev. 1999, 107, 123-136. [CrossRef]

78. Subramanian, A.; Salhab, M.; Mokbel, K. Oestrogen producing enzymes and mammary carcinogenesis: A review. Breast Cancer Res. Treat. 2008, 111, 191-202. [CrossRef]

79. Reiner, A.P.; Aragaki, A.K.; Gray, S.L.; Wactawski-Wende, J.; Cauley, J.A.; Cochrane, B.B.; Kooperberg, C.L.; Woods, N.F.; LaCroix, A.Z. Inflammation and thrombosis biomarkers and incident frailty in postmenopausal women. Am. J. Med. 2009, 122, 947-954. [CrossRef]

80. Leng, S.X.; Xue, Q.L.; Tian, J.; Walston, J.D.; Fried, L.P. Inflammation and frailty in older women. J. Am. Geriatr. Soc. 2007, 55, 864-871. [CrossRef]

81. Gale, C.R.; Baylis, D.; Cooper, C.; Sayer, A.A. Inflammatory markers and incident frailty in men and women: The English Longitudinal Study of Ageing. Age 2013, 35, 2493-2501. [CrossRef] [PubMed]

82. Netz, Y.; Ben-Zaken, S.; Zeev, A.; Dunsky, A. Correlates of early-stage frailty-sleep, fitness, oxidative stress, and BMI. Front. Med. 2021, 7, 594710. [CrossRef] [PubMed]

83. Baptista, G.; Dupuy, A.M.; Jaussent, A.; Durant, R.; Ventura, E.; Sauguet, P.; Picot, M.C.; Jeandel, C.; Cristol, J.P. Low-grade chronic inflammation and superoxide anion production by NADPH oxidase are the main determinants of physical frailty in older adults. Free Radic. Res. 2012, 46, 1108-1114. [CrossRef] [PubMed]

84. Fernández-Garrido, J.; Ruiz-Ros, V.; Buigues, C.; Navarro-Martinez, R.; Cauli, O. Clinical features of prefrail older individuals and emerging peripheral biomarkers: A systematic review. Arch. Gerontol. Geriatr. 2014, 59, 7-17. [CrossRef]

85. Morley, J.E.; Vellas, B.; Van Kan, G.A.; Anker, S.D.; Bauer, J.M.; Bernabei, R.; Cesari, M.; Chumlea, W.C.; Doehner, W.; Evans, J.; et al. Frailty consensus: A call to action. J. Am. Med. Dir. Assoc. 2013, 14, 392-397. [CrossRef]

86. Walston, J.; Robinson, T.N.; Zieman, S.; McFarland, F.; Carpenter, C.R.; Althoff, K.N.; Andrew, M.K.; Blaum, C.S.; Brown, P.J.; Buta, B.; et al. Integrating frailty research into the medical specialties-Report from a U13 conference. J. Am. Geriatr. Soc. 2017, 65, 2134-2139. [CrossRef]

87. Martinez-Tapia, C.; Laurent, M.; Paillaud, E.; Caillet, P.; Ferrat, E.; Lagrange, J.L.; Rwabihama, J.P.; Allain, M.; Chahwakilian, A.; Boudou-Rouquette, P.; et al. Predicting frailty and geriatric interventions in older cancer patients: Performance of two screening tools for seven frailty definitions-ELCAPA cohort. Cancers 2022, 14, 244. [CrossRef]

88. Jauhari, Y.; Gannon, M.R.; Dodwell, D.; Horgan, K.; Tsang, C.; Clements, K.; Medina, J.; Tang, S.; Pettengell, R.; Cromwell, D.A. Addressing frailty in patients with breast cancer: A review of the literature. Eur. J. Surg. Oncol. 2020, 46, 24-32. [CrossRef] 